\title{
Comparison between Treatment Outcomes of Titanium Miniplates and Titanium Lag Screws in Fixation of Mandibular Symphysis and Parasymphysis Fractures
}

\author{
Udit Prakash ${ }^{1 *}$, Moin Iftikhar Shapoo ${ }^{1}$, Peyush Pratap Singh \\ Sikarwar ${ }^{2}$, Bhavika Pol Vhatkar ${ }^{3}$, Ayush Garg ${ }^{4}$ and Priya Yadav ${ }^{5}$ \\ ${ }^{1}$ Assistant Professor, Department of Oral and Maxillofacial Surgery, Maharana \\ Pratap College of Dentistry and Research Centre, Gwalior, Madhya Pradesh, India \\ ${ }^{2}$ Department of Oral and Maxillofacial Surgery, Maharana Pratap College of \\ Dentistry and Research Centre, Gwalior, Madhya Pradesh, India \\ ${ }^{3}$ Assistant Professor, Oral Medicine and Radiology Department, Dr D Y Patil School \\ of Dentistry, Navi Mumbai, India \\ ${ }^{4}$ Resident, OMFS Jaipur, India \\ ${ }^{5} P G$ Third Year Resident, Department of Oral and Maxillofacial Surgery, People's \\ College of Dental Science and Research Centre, Bhopal, India \\ *Corresponding Author: Udit Prakash, Assistant Professor, Department of Oral and \\ Maxillofacial Surgery, Maharana Pratap College of Dentistry and Research Centre, \\ Gwalior, Madhya Pradesh, India.
}

Received: July 16, 2021

Published: July 29, 2021

(C) All rights are reserved by Udit Prakash., et al.

\begin{abstract}
Introduction: For a long time Champy's Miniplates and Lag screws remained as primary methods of fixation of mandibular fractures. Both miniplates and lag screws have their specific advantages. This prospective study was conducted to compare the efficacy and surgical outcomes of treatment of mandibular fractures using either titanium miniplates or titanium lag screws for internal fixation.

Materials and Methods: 200 patients were selected for the study and they were evaluated pre and post-operatively on various parameters. Patients were divided equally into two groups. One group was treated with titanium miniplates (group M) and other group by titanium lag screws (group L). Operating time was recorded and post-operative complications were observed over regular interval of time.

Results: Mean preoperative distance at various points on fracture line in group M was 1.7930, 2.6440, 2.4330 respectively while in group L it was $2.7560,2.4950,2.2230$ respectively. There was significant decrease in distance between fracture segments postoperatively. The mean operative time for titanium lag screw fixation was 80.10 mins while for miniplates it was 100.50 mins. Postoperative complications were less in group L when compared to group $\mathrm{M}$.

Conclusion: Lag screw has definite advantage over miniplates in terms of time duration of surgery, proper reduction and postoperative complications.
\end{abstract}

Keywords: Titanium Miniplates; Titanium Lag Screws; Mandibular Symphysis; Parasymphysis Fractures 


\section{Introduction}

Face is a window through which we perceive the world around us and the world notes us. Injuries to face results in devastating physical and emotional sequelae. Maxillofacial injuries are one of the most important health problems worldwide. Fractures of the mandible account for $39 \%$ - 59\% of all maxillofacial fractures [1]. Being the largest and strongest facial bone, it is the tenth commonly injured bone in the body next to the nasal bone fractures [2].

A study by Haug., et al. showed that there is a 6:2:1 proportion exists among the mandible, zygomatic and maxillary fractures [3]. Road traffic accidents (RTA), falls and sports related injuries remained the most common etiological factors of facial fractures [3].

The selection of the size, shape and material for reducing fracture is greatly dependent on biomechanical behaviour of mandible.

Management of mandibular fractures and their evolution to the current times of miniplate osteosynthesis, travelled a long path starting from barrel bandaging, splints and external fixators. It was late 1940 when use of internal wires were started for suspension and approximation of mandibular fractures [4]. In late $1960 \mathrm{Luhr}$ and Perren revolutionized mandible fracture treatment by development of plates with compression holes [5]. The compression plates were bulky and high post surgical complications compelled surgeons to develop a further advanced and more favourable mode of osteosynthesis. Michelet in late 1973 succeeded in developing a novel method of osteosynthesis and put forward the concept of Miniplate osteosynthesis which was further developed and modified by Champy and Ladde [6].

In 1973 spiessl introduced lag screws for management of mandibular fracture which was based on the concept of axial compression of fractured bony segments. In this method long lag screws are inserted across the fracture segments at right angle to the fracture line.

The present study deals with the comparison of the treatment outcomes of 2 most common methods of open reduction and internal fixation of mandible - miniplates and lag screws in mandible fractures in 200 patients.

\section{Materials and Methods}

200 patients of mandibular fractures (symphysis and parasymphysis) were selected and they were randomly divided into two groups of 100 each. One group was treated with titanium miniplates (group M) and other group by titanium lag screws (group L), after doing MMF and routine investigations.

The inclusion criteria were:

- Mandibular parasymphysis and symphysis fractures.

- Patients medically fit for surgery under GA or LA.

- Patients within the age group of 16 - 60 years.

The exclusion criteria were:

- Comminuted mandibular fractures.

- Pathological fractures.

- Hematological disorders or any other disorders contraindicating surgery.

Post-operative Orthopantomograph (OPG) were taken and patients were recalled at 1, 3 and 6 weeks after surgery. Operative time (time from incision to last suture), post-operative swelling and biting efficiency (ability to eat hard and soft food) at 1, 3 and 6 weeks were noted. Post-operative parameters wiz; Occlusion, infection, wound dehiscence, primary stability of fracture segments and malunion/non-union of fractures were also noted.

Pre and post-operative radiographic evaluation was done by measuring the distance between the fractured segments by using digital vernier calipers on the OPG. The X-rays were performed within 2 days after surgery. The OPG was traced on a tracing paper. On the traced paper, a line was drawn along the fracture line keeping the same landmark for both pre-operative and post-operative OPG of the patient. Three perpendicular lines were projected onto the fracture line for reproducible measure points. These lines divide the fracture lines into 2 equal parts. Onto these three points, the distance between the fracture segments was calculated using a precision digital vernier caliper (150 mm, 6 inches) shown in figure 1 . These three points was named as point 1 , point 2 and point 3 from the upper to lower border as shown in figure 2 . The results were compared for Group M and Group L. Results were evaluated using Student-t test and Chi square test.

\section{Results}

The combined mean age of patients in both the groups was 37 years where the minimum age was 21 years while the maximum age was 50 years. This shows that persons in the middle age group are more susceptible to mandibular fractures.

Citation: Udit Prakash., et al. "Comparison between Treatment Outcomes of Titanium Miniplates and Titanium Lag Screws in Fixation of Mandibular Symphysis and Parasymphysis Fractures". Acta Scientific Otolaryngology 3.8 (2021): 139-146. 


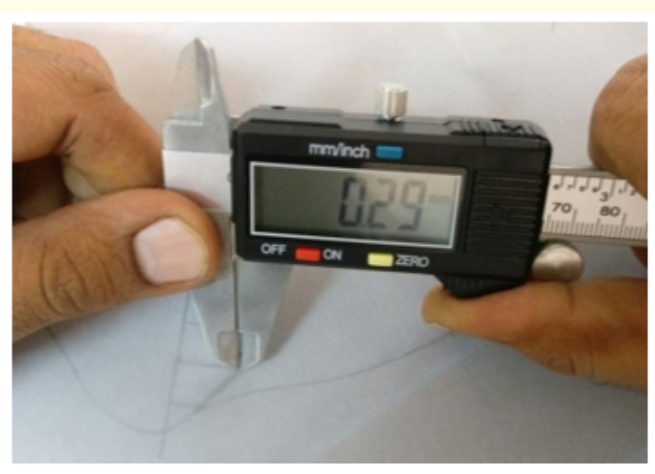

Figure 1: Pyrolysis products from microwave pyrolysis of agro-residue.

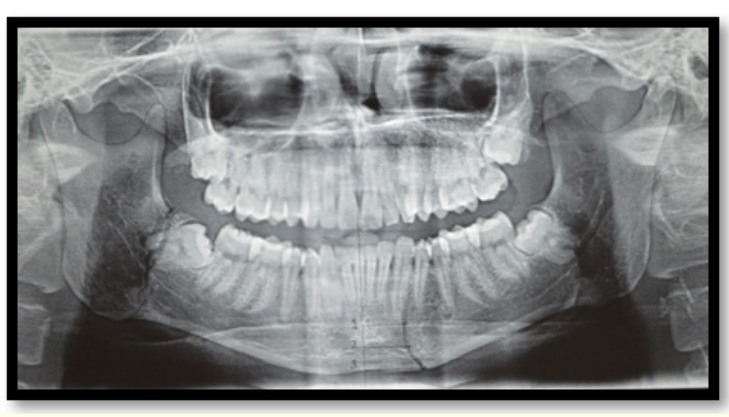

Figure 2

Out of 200 patients included in the study, 170 patients were male and 30 were female. This signifies clearly that males are more prone to mandible fractures than females $(6: 1)$. The foremost cause of mandibular fracture was road traffic accident (53.30\%) followed by physical assault/interpersonal violence (23.3\%), fall (20\%)and sports (3.3\%).

The radiographic distance between fracture segments was assessed both pre-operatively and post-operatively by using digital vernier caliper at 3 different points along the fracture line. They were named as 1, 2 and 3 from superior to inferior border and was at equal distance from each other. The points 1,2 and 3 were compared between the 2 groups and results were evaluated.
Preoperative radiographic evaluation Point 1

\begin{tabular}{|l|c|c|c|c|}
\hline Groups & N & Mean & $\begin{array}{c}\text { Std. } \\
\text { Deviation }\end{array}$ & $\begin{array}{c}\text { Std. Error } \\
\text { Mean }\end{array}$ \\
\hline Group L & 100 & 2.7560 & 1.10846 & 0.35053 \\
\hline Group M & 100 & 1.7930 & 1.16325 & 0.36785 \\
\hline
\end{tabular}

Table 1: Pre-operative radiographic evaluation at point 1.

Table 1 indicates that there was no significant difference found between Pre-operative radiographic evaluation mean distance between fracture segments of Lag Screw and Miniplate Groups at Point 1 , as the p-value was 0.074 which was greater than 0.05 .

Point 2

\begin{tabular}{|l|c|c|c|c|}
\hline Groups & N & Mean & $\begin{array}{c}\text { Std. } \\
\text { Deviation }\end{array}$ & Std. Error Mean \\
\hline Group L & 100 & 2.4950 & 1.23905 & 0.39182 \\
\hline Group M & 100 & 2.6440 & 2.14783 & 0.67920 \\
\hline
\end{tabular}

Table 2: Pre-operative radiographic evaluation at point 2.

Table 2 indicates that there was no significant difference found between Pre-operative radiographic evaluation mean distance between fracture segments of Lag Screw and Miniplate Groups at Point 2 , as the p-value was 0.851 which was greater than 0.05 .

Point 3

\begin{tabular}{|l|c|c|c|c|}
\hline Groups & N & Mean & $\begin{array}{c}\text { Std. } \\
\text { Deviation }\end{array}$ & $\begin{array}{c}\text { Std. Error } \\
\text { Mean }\end{array}$ \\
\hline Group L & 100 & 2.2230 & 0.88164 & 0.27880 \\
\hline Group M & 100 & 2.4330 & 2.83116 & 0.89529 \\
\hline
\end{tabular}

Table 3: Pre-operative radiographic evaluation at point 3.

Table 3 indicates that there was no significant difference found between Pre-operative R/G Evaluation Mean distance between fracture segments of Lag Screw and Miniplate Groups at Point 3, as the p-value was 0.825 which was greater than 0.05 .

The mean distance between the fracture segments was found more at point 1 in Group $\mathrm{L}$ while it was found more in Group $\mathrm{M}$ at point 2 and point 3 . Though, there was no significant difference 
Comparison between Treatment Outcomes of Titanium Miniplates and Titanium Lag Screws in Fixation of Mandibular Symphysis and Parasymphysis Fractures

found at any point and $\mathrm{p}$ value was found more than 0.5 at every point.

Post-operative radiographic evaluation

Point 1

\begin{tabular}{|l|c|c|c|c|}
\hline \multicolumn{1}{|c|}{ Groups } & N & Mean & $\begin{array}{c}\text { Std. } \\
\text { Deviation }\end{array}$ & $\begin{array}{c}\text { Std. Error } \\
\text { Mean }\end{array}$ \\
\hline Group L & 100 & 1.4200 & 0.71062 & 0.22472 \\
\hline Group M & 100 & 1.7780 & 1.04155 & 0.32937 \\
\hline
\end{tabular}

Table 4: Post-operative radiographic evaluation at point.

Table 4 indicates that there was a significant difference found between Post-operative R/G Evaluation Mean distance between fracture segments of Lag Screw and Miniplate Groups at Point 1, as the p-value was 0.0381 which was less than 0.05 .

Point 2

\begin{tabular}{|l|c|c|c|c|}
\hline \multicolumn{1}{|c|}{ Groups } & N & Mean & Std. Deviation & $\begin{array}{c}\text { Std. Error } \\
\text { Mean }\end{array}$ \\
\hline Group L & 100 & 1.2120 & 0.52101 & 0.15963 \\
\hline Group M & 100 & 1.2780 & 0.88332 & 0.18446 \\
\hline
\end{tabular}

Table 5: Post-operative radiographic evaluation at point 2.

Table 5 indicates that there was a significant difference found between Post-operative R/G Evaluation Mean distance between fracture segments of Lag Screw and Miniplate Groups at Point 2, as the p-value was 0.0867 which was less than 0.05 .

\section{Point 3}

\begin{tabular}{|l|c|c|c|c|}
\hline Groups & N & Mean & $\begin{array}{c}\text { Std. } \\
\text { Deviation }\end{array}$ & $\begin{array}{c}\text { Std. Error } \\
\text { Mean }\end{array}$ \\
\hline Group L & 100 & 0.9330 & 0.52116 & 0.19130 \\
\hline Group M & 100 & 1.4120 & 0.95809 & 0.27648 \\
\hline
\end{tabular}

Table 6: Post-operative radiographic evaluation at point 3.

Table 6 indicates that there was a significant difference found between post-operative radiographic valuation mean distance between fracture segments of Lag Screw and Miniplate Groups at Point 3 , as the p-value was 0.0375 which was less than 0.05 .
The mean radiographic distance between the fracture segments was found more in Group M at each point (point 1, 2 and 3) than in Group L. there was also significant difference found between the two groups at each point as p value was found less than 0.5 .

\section{Operating time duration}

The operating time duration was calculated in minutes in Group $M$ and Group L from the time of incision till the time of last suture.

\begin{tabular}{|l|c|c|c|c|}
\hline Groups & N & Mean & $\begin{array}{c}\text { Std. } \\
\text { Deviation }\end{array}$ & $\begin{array}{c}\text { Std. Error } \\
\text { Mean }\end{array}$ \\
\hline Group L & 100 & 80.1000 & 9.08540 & 2.87305 \\
\hline Group M & 100 & 100.5000 & 13.21825 & 4.17998 \\
\hline
\end{tabular}

Table 7: Operating time duration.

Table 7 indicates that there was a significant difference found between Operating Time of Lag Screw and Miniplate Groups, as the p-value was 0.001 which was less than 0.05 .The operative time for titanium lag screw fixation was found significantly less than in titanium miniplate fixation.

Post-operative parameters

Swelling, sensory deficit and biting efficiency of the patient was calculated at $1^{\text {st }}, 3^{\text {rd }}$ and $6^{\text {th }}$ week post-operatively and the results were analysed by chi-square test. Other parameters wiz. Occlusion, primary stability, infection, wound dehiscence and mal-union/ non-union of fractures were also analysed.

$1^{\text {st }}$ week

Swelling

\begin{tabular}{|l|c|c|c|c|}
\hline \multicolumn{2}{|c|}{} & \multicolumn{2}{c|}{ Swelling } & \multirow{2}{*}{ Total } \\
\cline { 3 - 4 } \multicolumn{2}{|c|}{} & Absent & Present & \\
\hline \multirow{2}{*}{ Groups } & Group L & 40 & 60 & 100 \\
\cline { 2 - 5 } & Group M & 0 & 100 & 100 \\
\hline Total & 40 & 160 & 200 \\
\hline
\end{tabular}

Table 8: Post-operative parameters (1 ${ }^{\text {ST }}$ week)-swelling.

Table 8 indicates that there was a significant difference found between absents and presents rate of swelling in Lag Screw and Miniplate groups, as the p-value was 0.036 which was less than 0.05 . 
Comparison between Treatment Outcomes of Titanium Miniplates and Titanium Lag Screws in Fixation of Mandibular Symphysis and Parasymphysis Fractures

Thus, post-operative swelling was seen less in Group L than in Group $\mathrm{M}$ at $1^{\text {st }}$ week post-operatively.

Sensory deficit

\begin{tabular}{|l|c|c|c|c|}
\hline \multicolumn{2}{|c|}{} & \multicolumn{2}{|c|}{ Sensory } & \multirow{2}{*}{ Total } \\
\cline { 3 - 4 } \multicolumn{2}{|c|}{} & Absent & Present & \\
\hline \multirow{2}{*}{ Groups } & Group L & 100 & 0 & 100 \\
\cline { 2 - 5 } & Group M & 90 & 10 & 100 \\
\hline \multicolumn{2}{|l|}{ Total } & 190 & 10 & 200 \\
\hline
\end{tabular}

Table 9: Post-operative parameters ( $1^{\mathrm{ST}}$ week)-sensory deficit.

Table 9 indicates that there was no statistically association found between absents and presents rate of Sensory Deficit in Lag Screw and Miniplate groups, as the p-value was 0.305 which was greater than 0.05 . Group L has less incidences of paresthesia at $1^{\text {st }}$ week post-operatively than Group M, but the difference was not statistically significant.

\section{Biting efficiency}

\begin{tabular}{|c|c|c|c|c|}
\hline & \multicolumn{2}{|c|}{ Biting efficiency } & \multirow{2}{*}{ Total } \\
\hline & & Liquid & Semi-solid & \\
\hline \multirow[t]{2}{*}{ Groups } & Group L & 80 & 20 & 100 \\
\hline & Group M & 100 & 0 & 100 \\
\hline \multicolumn{2}{|c|}{ Total } & 180 & 20 & 200 \\
\hline
\end{tabular}

Table 10: Post-operative parameters $\left(1^{\mathrm{ST}}\right.$ week)-biting efficiency.

Table 10 indicates that there was no statistically association found between absents and presents rate of Biting Efficiency in Lag Screw and Miniplate groups, as the p-value was 0.136 which was greater than 0.05. Patients in Group L fared better in biting efficiency, as 2 out of 10 patients in Group L were able to chew semisolid food, but no patients in Group M were able to chew. The different was not statistically significant though.

$3^{\text {rd }}$ week

Swelling

\begin{tabular}{|l|c|c|c|c|}
\hline \multicolumn{2}{|c|}{} & \multicolumn{2}{c|}{ Swelling } & \multirow{2}{*}{ Total } \\
\cline { 3 - 4 } \multicolumn{2}{|c|}{} & Absent & Present & \\
\hline \multirow{2}{*}{ Groups } & Group L & 80 & 20 & 100 \\
\cline { 2 - 4 } & Group M & 40 & 60 & 100 \\
\hline Total & 120 & 80 & 200 \\
\hline
\end{tabular}

Table 11: Post-operative parameters ( $3^{\text {rd }}$ week)-swelling.
Table 11 indicates that there was no statistically association found between absents and presents rate of swelling in Lag Screw and Miniplate groups, as the p-value was 0.068 which was greater than 0.05.At $3^{\text {rd }}$ week post-operatively, swelling was seen in just 2 cases of Group L, while it was present in 6 out of 10 cases of Group M. There was a clear improvement in Group L, but the difference was not found statistically significant at the end of $3^{\text {rd }}$ week.

\section{Sensory deficit}

\begin{tabular}{|l|c|c|c|c|}
\hline \multicolumn{2}{|c|}{} & \multicolumn{2}{c|}{ Sensory } & \multirow{2}{*}{ Total } \\
\cline { 3 - 5 } \multicolumn{2}{|c|}{} & Absent & Present & \\
\hline \multirow{2}{*}{ Groups } & Group L & 100 & 0 & 100 \\
\cline { 2 - 5 } & Group M & 80 & 20 & 100 \\
\hline \multirow{2}{*}{ Total } & 180 & 20 & 200 \\
\hline
\end{tabular}

Table 12: Post-operative parameters ( $3^{\text {rd }}$ week)-sensory deficit.

Table 12 indicates that there was no statistically association found between absents and presents rate of Sensory Deficit in Lag Screw and Miniplate groups, as the $\mathrm{p}$-value was 0.136 which was greater than 0.05 . The sensory deficit was found in 2 patients in Group $\mathrm{M}$ at the end of $3^{\text {rd }}$ week, but was absent in Group L, which shows that Group L fared better in terms of sensory deficit than Group M, though the difference was not statistically significant.

Biting efficiency

\begin{tabular}{|l|c|c|c|c|c|}
\hline \multirow{2}{*}{\multicolumn{2}{|c|}{ Liquid }} & \multicolumn{3}{c|}{ Biting efficiency } & \multirow{2}{*}{ Total } \\
\cline { 3 - 6 } & Semi- solid & Normal & & \\
\hline \multirow{2}{*}{ Groups } & Group L & 0 & 80 & 20 & 100 \\
\cline { 2 - 5 } & Group M & 10 & 90 & 0 & 100 \\
\hline \multirow{2}{*}{ Total } & 10 & 170 & 20 & 200 \\
\hline
\end{tabular}

Table 13: Post-operative parameters ( $3^{\text {rd }}$ week)-biting efficiency.

Table 13 indicates that there was no statistically association found between absents and presents rate of Biting Efficiency in Lag Screw and Miniplate groups, as the p-value was 0.217 which was greater than 0.05. 20 patients in Group $L$ were able to chew normal diet, while 80 were on semi-solid diet at the end of $3^{\text {rd }}$ week. In Group M, 1 patient was still on liquid diet, while 90 were on semisolid diet, none were able to chew normal food. This shows a clear benefit in lag screw fixation in terms of return of normal dietary habits of the patient, though the difference was not statistically significant. 
Comparison between Treatment Outcomes of Titanium Miniplates and Titanium Lag Screws in Fixation of Mandibular Symphysis and Parasymphysis Fractures

$6^{\text {th }}$ week

Swelling

\begin{tabular}{|l|c|c|c|c|}
\hline \multicolumn{2}{|c|}{} & \multicolumn{2}{c|}{ Swelling } & \multirow{2}{*}{ Total } \\
\cline { 3 - 4 } \multicolumn{2}{|c|}{} & Absent & Present & \\
\hline \multirow{2}{*}{ Groups } & Group L & 100 & 0 & 100 \\
\cline { 2 - 4 } & Group M & 90 & 10 & 100 \\
\hline \multirow{2}{*}{ Total } & 190 & 10 & 200 \\
\hline
\end{tabular}

Table 14: Post-operative parameters ( $6^{\text {th }}$ week)-swelling.

Table 14 indicates that there was no statistically association found between absents and presents rate of swelling in Lag Screw and Miniplate groups, as the $\mathrm{p}$-value was 0.305 which was greater than 0.05 .

Group L fared better than Group M in comparison of post-operative swelling as only 1 patient has swelling at the end of $6^{\text {th }}$ week, though the difference was not statistically significant.

\section{Sensory deficit}

No difference was found between the two groups at $6^{\text {th }}$ week.

\section{Biting efficiency}

\begin{tabular}{|l|c|c|c|c|}
\hline \multicolumn{2}{|c|}{} & \multicolumn{2}{|c|}{ Biting efficiency } & \multirow{2}{*}{ Total } \\
\cline { 3 - 4 } \multicolumn{2}{|c|}{} & Semi-solid & Normal & \\
\hline \multirow{2}{*}{ Groups } & Group L & 0 & 100 & 100 \\
\cline { 2 - 4 } & Group M & 30 & 70 & 100 \\
\hline \multirow{2}{*}{ Total } & 30 & 170 & 200 \\
\hline
\end{tabular}

Table 15: Post-operative parameters ( $6^{\text {th }}$ week)-biting efficiency.

Table 15 indicates that there was no statistically association found between absents and presents rate of Biting Efficiency in Lag Screw and Miniplate groups, as the p-value was 0.060 which was greater than 0.05 . Earlier return of normal diet of patients were seen at $6^{\text {th }}$ week also in Group M than in Group L, but the difference was not found statistically significant.

\section{Infection}

Table 16 indicates that there was no statistically association found between absents and presents rate of Infection in Lag Screw and Miniplate groups, as the p-value was 0.305 which was greater than 0.05 . The incidence of infection was found in just 1 case of miniplates which was due to presence of tooth in the fracture line.

\begin{tabular}{|l|c|c|c|c|}
\hline \multicolumn{2}{|c|}{} & \multicolumn{2}{|c|}{ Infection } & \multirow{2}{*}{ Total } \\
\cline { 3 - 4 } \multicolumn{2}{|c|}{} & Absent & Present & \\
\hline \multirow{3}{*}{ Groups } & Group L & 100 & 0 & 100 \\
\cline { 2 - 5 } & Group M & 90 & 10 & 100 \\
\hline \multirow{2}{*}{ Total } & 190 & 10 & 200 \\
\hline
\end{tabular}

Table 16: Post-operative parameters-infection.

It resolved after removing the infected tooth at $6^{\text {th }}$ week. There was no statistical difference found between the two groups.

No cases was seen of mal-union/non-union of fracture segments and wound dehiscence in both the groups. Post-operative occlusion was found normal and the fracture segments were found to be stable in both the groups.

\section{Discussion}

The study evaluated the efficacy of miniplates and lag screws in open reduction and internal fixation of mandibular symphysis/ parasymphysis fractures. In our study, 100 fractures i.e. group A were treated with $2.5 \mathrm{~mm} / 3.0 \mathrm{~mm}$ single conventional miniplate and 100 fractures i.e. group B were treated with $2.5 \mathrm{~mm} / 3.0 \mathrm{~mm} \mathrm{x}$ 8/10/12 mm lag screws.

In our study mean age of patients was 35.6 years of group $L$ and 39.2 years of group $M$ and total mean age was 37.2 years. Our study showed higher frequency of mandibular fracture in males compared to females and the ratio was 6:1 respectively. This variation in frequency was attributed to the fact that outdoor activities in general and particularly motor cycles are driven by male and RTA due to motor cycle's collisions is the commonest cause of these fractures. The foremost cause of mandibular fracture was road traffic accident (53.30\%) followed by assault (23.3\%) fall (20\%), sports (3.3\%). which is similar to other studies [1-3].

The time it took to complete the procedure was measured from the moment the incision was made to the time the last stitch was inserted. The average operation time (in hours) was 100.5 minutes for Group M and 80.1 minutes for Group L. Because the timeconsuming job of plate bending and adaption is eliminated, lag screw fixation is substantially faster. According to Ellis and Ghali, lag screws can be inserted faster than miniplates because the latter require contouring and adaptation, which can take time given the complexity of anterior mandibular contour [7]. There are many 
advantages of a short surgical procedure as elucidated by various authors like brief hospitalization and decreased incidence of infectious complications, which significantly lowers the financial burden.

Primary stabilization was achieved in all of the cases of both miniplates and lag screws. After releasing the MMF, it appears that manipulating the jaw segments to check for stability is important in cases of lag screw fixation.

There was one incidence of drill breakage in miniplate group and no such incidence in lag screw group. Tiwana., et al. [8] encountered drill breakage in $5.9 \%$ of cases of lag screw fixation. This problem was not encountered in the present study. It's possible that this is due to a failure to recognise the proper drilling angle required to engage the opposite fracture cortex. Furthermore, all efforts were taken to engage the opposite cortex as perpendicularly as feasible while drilling the traction hole, and to prevent pushing the drill. None of the patients had any malocclusion. Tuovinen., et al. [9] reported that malocclusion developed in $4.7 \%$ of patients treated with miniplates, where Cawood [10] reported malocclusion in $6 \%$ of patients treated with miniplates in symphysis region fractures; these observations are not in concurrence with those of the present study.

It has been recommended that titanium plates should be removed in case of infection at fracture site. Removal of titanium plates has always been a point of controversy. The need for a second process of plate removal every 3 - 6 months was one of the disadvantages of using the miniplate method. Routine removal is necessary to avoid stress shielding of repaired fractures as well as the potential toxicity of the corroded metal. None of the patients in group $\mathrm{L}$, on the other hand, required lag screw removal due to postoperative infection.

In the present study, the overall incidence of postoperative complications in Group L was 60\% while it was $100 \%$ in Group M. At $3^{\text {rd }}$ week, post-operative swelling was $20 \%$ in Group L while it was $60 \%$ in Group M. At $6^{\text {th }}$ week, it was $10 \%$ in Group M while none in Group L. All the cases of post-operative was resolved by $12^{\text {th }}$ week.

Two cases was of paresthesia was seen in the region of mental nerve distribution in Group $M$ which were cases of angle fracture and parasymphysis fracture. Paresthesia also resolved by 6 weeks.
Recent onset neurosensory deficit in immediate postoperative period could also occur due to inadvertent damage or traction on nerve during intraoperative manipulation of fracture fragments. No cases was observed of wound dehiscence in both the groups, primarily due to usage of external support with adhesive elastic bandages.

Their masticatory efficiency was evaluated and general trends towards intake of soft diet were seen in both groups for $1^{\text {st }}, 3^{\text {rd }}, 6^{\text {th }}$ and $12^{\text {th }}$ weeks. There was an improvement in biting efficiency of patients of Group L. In the past four decades, there has been an increasing interest in obtaining more immediate return to normal function by using different methods of direct function with an open reduction allowing anatomical reduction of the fragments. Improved masticatory function favours early recovery of jaw function in terms of mouth opening and bite force, decreases weight loss and also provides rapid return of the patient's function at both physiological and psychological levels.

We did a radiographic analysis of the postoperative fracture gap between Group M and Group L in our study, the mean postoperative radiographs demonstrated a significant reduction in fracture gap in Group L as compared to the Group M, which is in concurrence with the study of Heidrun Schaaf., et al [11]. Measurement of the fracture gap has not been performed regularly in studies reported in the literature. The lag-screw method resulted in smaller fracture gaps than the miniplate groups. Smaller gap areas, when immobilized by neighboring contact zones, still permit direct lamellar ossification inside the gap. It is generally accepted that reduction and fixation of the fracture to align the fragments in contact promotes bone healing. Moreover, a direct correlation between the fracture-gap width and the healing process is given in the literature; if the fracture-gap width is larger than $2 \mathrm{~mm}$, then bone healing is delayed. Large fracture gaps cause a delay in fracture healing, as demonstrated in post-operative evaluation (Biting Efficiency), experimental and clinical investigations [12,13]. A good reduction of a fracture with small interfragmentary gaps is important for its revascularization and healing.

The main characteristics of lag screw fixation is that it provides excellent primary bone healing due to fragment compression, but it also offers limited stripping of the periosteum. It enables normal bone healing regardless of saliva leakage or infection. Drilling can 
be safer and simpler with insertion canals, and the screw distortion can be prevented by drilling sleeves, which maintain the drilling direction with both $1.5 \mathrm{~mm}$ and $2.0 \mathrm{~mm}$ drills. In opinion of Dediol., et al. lag screws provide excellent stability and ensure enough compression of the fragments to promote primary bone healing. The complication rate with their use is low and comparable to that of miniplate fixation, which makes lag screws at least equally effective. It is also economical for the patient to use lag screw instead of miniplates.

\section{Conclusion}

The study shows a clear benefit of lag screws over miniplates in case of time duration of surgery and post-operative radiographic distance between fracture segments, which supports the concept that lag screws provides rigid fixation while miniplates provides semirigid fixation between fracture segments. The study also shows a considerable improvement in swelling and sensory deficit in cases of lag screws over miniplates. Also, the ability of patient to return to normal dietary habits is seen earlier in cases of lag screws than in miniplates.

The small sample size and limited follow-up could be considered as the limitations of this study. Further study with larger sample size and log-term follow-up period is required for establishment of this result.

\section{Bibliography}

1. Shah N., et al. "Analysis of Mandibular Fractures: A 7-year Retrospective Study". Annals of Maxillofacial Surgery 9.2 (2019): 349-354.

2. Krishnaraj S and Chinnasamy R. "A 4-year retrospective study of mandibular fractures in a South Indian city". The Journal of Craniofacial Surgery 18.4 (2007): 776-780.

3. Haug RH., et al. "Cranial fractures associated with facial fractures: a review of mechanism, type, and severity of injury". Journal of Oral and Maxillofacial Surgery 52.7 (1994): 729-733.

4. Devlin DH. "A historical review of dental and facial skeletal trauma". The Journal of the California Dental Association 24.2 (1996): 29-34.

5. Luhr HG., et al. "Comparative studies between the extraoral and intraoral approach to compression STCO synthesis of mandibular fractures". In Hjorting-Hansen E. (edition): Oral and Maxillofacial Surgery. Quintessence, Chicago (1985): 133.

6. Michelet FX., et al. "Osteosynthesis with miniaturized screw plates in maxillofacial surgery". Journal of Oral and Maxillofacial Surgery 1 (1973): 79-84.

7. Ellis E and Ghali GE. "Lag screw fixation of anterior mandibular fractures”. Journal of Oral and Maxillofacial Surgery 49.1 (1991): 13-21.

8. Tiwana Paul S., et al. "Lag screw fixation of anterior mandibular fractures: a retrospective analysis of intraoperative and postoperative complications". Journal of Oral and Maxillofacial Surgery 65.6 (2007): 1180-1185.

9. Tuovinen Veikko., et al. "A retrospective analysis of 279 patients with isolated mandibular fractures treated with titanium miniplates". Journal of Oral and Maxillofacial Surgery 52.9 (1994): 931-935.

10. Cawood JI. "Small plate osteosynthesis of mandibular fractures". British Journal of Oral and Maxillofacial Surgery 23.2 (1985): 77-91.

11. Schaaf Heidrun., et al. "Comparison of miniplate versus lagscrew osteosynthesis for fractures of the mandibular angle". Oral Surgery, Oral Medicine, Oral Pathology, Oral Radiology, and Endodontology 111.1 (2011): 34-40.

12. Reitzik Monty and Willem Schoorl Leyden. "Bone repair in the mandible: a histologic and biometric comparison between rigid and semirigid fixation". Journal of Oral and Maxillofacial Surgery 41.4 (1983): 215-218.

13. Goyal Manoj., et al. "A comparative evaluation of fixation techniques in anterior mandibular fractures using $2.0 \mathrm{~mm}$ monocortical titanium miniplates versus $2.4 \mathrm{~mm}$ cortical titanium lag screws". Journal of Maxillofacial and Oral Surgery 11.4 (2012): 442-450.

\section{Volume 3 Issue 8 August 2021 (C) All rights are reserved by Udit Prakash., et al.}

